\title{
Spark-Induced Breakdown Spectroscopy for Fuel-Air Equivalence Ratio Measurements at Internal Combustion Engine-Relevant Conditions
}

\author{
Thomas Kammermann $^{\mathrm{a}, \mathrm{b}}$, Laura Merotto ${ }^{\mathrm{a} *}$, Davide Bleiner ${ }^{\mathrm{a}, \mathrm{c}}$, Patrik Soltic $^{\mathrm{a}}$ \\ ${ }^{a}$ Empa, Swiss Federal Laboratories for Materials Science and Technology, Überlandstrasse \\ 129, 860 o Dübendorf, Switzerland \\ $b^{b}$ ETH Zurich, Swiss Federal Institute of Technology, Rämistrasse 101, 8092Zürich, Switzerland \\ c University of Zurich, Dept. of Chemistry, Winterthurerstrasse 190, CH 8057 Zurich, \\ Switzerland
}

Corresponding author:

$\operatorname{March} 18$, 2019

Email address: laura.merotto@empa.ch

This document is the accepted manuscript version of the following article:

Kammermann, T., Merotto, L., Bleiner, D., \& Soltic, P. (2019). Spark-induced breakdown spectroscopy for fuel-air equivalence ratio measurements at internal combustion engine-relevant conditions.

Spectrochimica Acta B: Atomic Spectroscopy. https://doi.org/10.1016/j.sab.2019.03.006

This manuscript version is made available under the CC-BY-NC-ND 4.0

license http://creativecommons.org/licenses/by-nc-nd/4.0/ 


\section{Abstract}

Spark-induced Breakdown Spectroscopy was used for local fuel-air equivalence ratio measurements of premix ed methane-air mixtures by a discharge from an inductive ignition system in a constant volume cell. Elemental emissions of hy drogen Balmer-alphaline $\left(\mathrm{H}_{\alpha}\right)$, nitrogen $\left(\mathrm{N}_{746}\right)$ and oxygen $\left(\mathrm{O}_{777}\right)$ were experimentally observed in the vicinity of the electrode gap, using a lens-coupled spectrometer and an intensified camera. After optimization of the gating strategy, the spectral emission features, i.e. line intensity ratios and peaks width (full width at half maximum) ratios were analyzed and their relation with the local fuel-air equivalence ratio at the spark plug was discussed, for operating pressures ranging from 10 to 20 bar.

Results showed that a change in pressure and temperature did not affect the spectral emissions' atomic peaks ratios, as long as the density was kept constant. For tests at constant temperature and at constant pressure, the peaks intensity ratios showed a linear correlation with local fuel-air equivalence ratio, while peaks width did not show noticeable changes. When pressure was varied, while keeping temperature and fuel-air equivalence ratio constant, a different behavior was observed: peaks intensity ratio were only slightly affected by pressure change, more prominently at fuel-rich conditions, while a peak broadening was clearly recognizable, as the peak width linearly increased with pressure.

Moreover, an additional optical setup involving a fiber-optic spark plug was implemented with the aim to adapt the proposed diagnostic tool to engines in operando. Comparisons with the lens setup showed that the developed technique is promising as a compact and versatile tool for applications involving local fuel-air equivalence ratio measurements at different ambient conditions.

Keywords: Spark-induced breakdown spectroscopy, fuel-air equivalence ratio, methane/air mixtures, natural gas engines, inductive discharge ignition

\section{Introduction}

Spark ignition (SI) engines have been inv estigated for several decades [1,2]. Nevertheless, optimization in terms of engine emissions and fuel economy is still challenging, due to the inherent characteristics of the premix ed combustion process, involving cycle-to-cycle variations. Ignition is known to have a major influence on the later stages of combustion process development (see for example [3,4]); in particular, the local fuel-air equivalence ratio $(\phi)$ at the spark plug is a crucial parameter for successful transition from ignition to early flame kernel and then later to a turbulent flame.

Lean-burn spark-ignition engines, i.e. when the fuel-air equivalence ratio is below the stoichiometric value, either perfectly premixed or with charge stratification around the spark plug, have been proved to improvefuel economy and reduce emissions $[5-10]$. Lean combustion results in more prominent cy cle-to-cycle variations in combustion and, consequently, in strong peak pressure fluctuations in the combustion chamber, eventually limiting the lean-burn operation range [11]. The ignition limits in 
terms of air to fuel ratio are strongly affected by the level of turbulence in the flow [12-14]. In turns, the rate of development of the initial flame kernel is affected by the local fuel concentration near the spark gap [6]. Therefore, concepts providing stable ignition conditions such as pre-chamber concepts [8,15-19] are also being explored for gas engines. The ultimate goal of the research in this framework is aimed at finding a minimal-inv asive diagnostics tool ensuring a precise measurement of the fuel-air equivalence ratio at the spark location in a running engine. Such a tool enables a better control of the fuel-air mixing process and ensures for example an extension of the current limits of $\phi$ ratio for engine operation. But it is also important in overall stoichiometric engine operation, especially if the combustion concept involves exhaust gas recirculation.

Natural gas-dedicated engines with properly adjusted combustion concepts can take advantage of the lower $\mathrm{CO}_{2}$ emissions compared to gasoline and diesel. The higher knock resistance of methane (i.e. the fact that it is less prone to igniting in an uncontrolled way during compression) allows enhancing the compression ratio compared to today's bivalent engines. But this also results in a more challenging environment to successfully initiate combustion, due to higher pressures at spark timing, resulting in an increased demand on the insulation resistance on the coil and spark plug. Recent dev elopments in gas engines include direct injection strategies. Rey nolds et. al. [20] have investigated a direct-injection lean-burn natural gas engine, showing that better fuel combustion is obtained at higher air to fuel ratios when a stratified charge is used. In a recent work from Biffiger and Soltic [21] the effect of different injection strategies for methane, hydrogen and hydrogen-enriched methane in a spark ignition engine has been investigated. The authors show that direct injection direction and timing affect mainly the early phase of combustion, whereas the later combustion phase is mainly influenced by the global stoichiometry and the fuel composition.

Since local fuel concentration at ignition time is one of the most critical parameters in determining flame stability in reacting flows, a pointwise measurement of $\phi$ at ignition timing is highly interesting. Laser-Induced Breakdown Spectroscopy (LIBS) is a well-established pointwise measurement technique $[22,23]$. The laser pulse used for mixture ignition can be successfully used as a diagnostic tool. Ferioli and Buckley [24] have demonstrated the possibility to obtain quantitative air-fuel equiv alence ratios for methane and propane in air. The applicability of LIBS in a single cylinder engine has been investigated by Joshi et. al. using the ratios of the $\mathrm{H}_{\alpha} / \mathrm{O}_{777}$, the $\mathrm{H}_{\alpha} / \mathrm{N}_{746}$ and $\mathrm{H}_{\alpha} / \mathrm{N}_{742-746}$ emission lines, showing promising results and suggesting this method for in-cylinder, cycle resolved fuel-air equivalence ratio measurements [25]. Such measurements have shown that the air-fuel ratio fluctuations do not correlate well with cycle-to-cycle variations in the combustion process and therefore are proposed to not be the major cause for those variations [26]. Phuoc and White [27] have discussed simultaneous laser ignition and equivalence ratio measurement using laser -induced gas breakdown in methane-air mixtures using $\mathrm{H}_{\alpha}(656 \mathrm{~nm})$ and the Otriplet near $777 \mathrm{~nm}$ for different laser energies at ambient conditions, revealing a linear dependency. However, lasers as an ignition source still suffer from limitations, such as invasiveness and complexity, that have so far prevented their full exploitation as an ignition source for internal combustion engines [28].

Spark-induced breakdown spectroscopy (SIBS), a measurement technique in which an electric spark discharge replaces the laser as a source of excitation, is a favorable alternative to laser spectroscopy methods in SI engines. In this technique, the signal detection and spectroscopy is similar to LIBS; 
however, spark generation occurs between two electrodes. The generated plasma is used as the light source to obtain information on the mixture concentration through spectral analy sis of the light emitted by the excited species. Since the plasma is generated through an electrical discharge, the characteristics of such a discharge affect the plasma features as well as the breakdown and recombination of molecules in the ignition area, ultimately dictating the spectr al emissions features. In particular, atomic emissions are stronger at early times after spark onset (breakdown), while molecular emissions are likely to appear at later stages [29,30]. As a consequence, the gating strategy, i.e. the time at which the spectral emission measurement is started (time delay after spark onset) and the acquisition duration (exposure time), is of major importance.

Spark-induced breakdown spectroscopy can be used as a diagnostic tool to characterize the local mixture conditions around the spark plug during the ignition attempt [11,31]. From SIBS spectral response, it has been shown that the local fuel-air equivalence ratio of different fuels such as methane [11,32], hydrogen [31], propane and iso-octane[33] can be derived, or plasma temperatures [34] determined. Ando and Kuwahara [35] and Fansler et al. [33] have reported measurements of the equivalence ratio at the spark gap using the ratio of $\mathrm{CN}(388 \mathrm{~nm})$ and $\mathrm{OH}$ $(306 \mathrm{~nm})$ emission intensity from the spark, using different fuels (propane, isooctane, and gasoline). They have determined the cycle-resolved local fuel/air ratio in the sparkgap, and evaluated the utility of SIBS as an engine diagnostic tool. However, they have reported that it is difficult to detect the equivalence ratio under lean mix ture conditions due to non-linearity of $\mathrm{CN} / \mathrm{OH}$ emission intensity ratio. In [31], the authors have sought to characterize the effects of ambient pressure at ignition timing on atomic line emissions and to improve the accuracy of SIBS measurements by taking into account the pressure dependency of atomic emissions. An exposure time of $150 \mu$ s have been used. Spectrally resolved emission spectra of plasma generated by a spark plug havebeen measured through an optical fiber housed in the center electrode of the spark plug. A calibration map representing the correlation of air-fuel ratio with both intensity ratio and pressure at ignition timing has been created by taking into account the effect of the corresponding pressure at ignition on spectral line intensity. The calibration line and calibration map have been subsequently used for quantitative measurements of the local airfuel ratio for both port injection and direct injection strategies to investigate the effects of the corresponding pressure at ignition timing on the accuracy of SIBS measurements. Nevertheless, the effect of gas temperature or density has not been taken into account. Additionally, the gating strategy optimization has not been discussed.

Kawahara et al. [32] have also determined the local equivalence ratio of a methane/air mixture in a laminar premixed flame using SIBS with a fiber-coupled intensified charge coupled device (ICCD) spectrometer. The emission intensities of $\mathrm{OH}, \mathrm{CN}$, and $\mathrm{NH}$ spectra under several equivalence ratio conditions have been measured and discussed as a way to measure the equivalence ratio using the intensity ratios of $\mathrm{CN} / \mathrm{OH}$ and $\mathrm{CN} / \mathrm{NH}$. Exposure times ranging from $50 \mu \mathrm{s}$ to $3 \mathrm{~ms}$ have been discussed. The intensity ratio of the $\mathrm{H}_{\alpha} / \mathrm{O}$ atomic emission lines has been used to measure the equivalence ratio of a premixed mixture and compared with the applicability of the intensity ratios of $\mathrm{CN} / \mathrm{OH}$ and $\mathrm{CN} / \mathrm{NH}$. However, their results have shown that the $\mathrm{H}_{\alpha} / \mathrm{O}$ intensity ratio is more suited for measuring the equivalence ratio than $\mathrm{CN} / \mathrm{NH}$ under lean mixture condition, thus suggesting that further investigation is needed in order to better understand the ongoing processes and to further 
improve SIBS technique reliability and versatility.

With this aim, SIBS as a diagnostic tool for methane/air and hydrogen enriched methane mixtures for engine relevant conditions was spatially and temporally investigated by Kammermann et al. [36], considering the spectral signal dependency on fuel-air equivalence ratio as well as on methane substitution by hydrogen, focusing on molecular spectral emissions of $\mathrm{OH}, \mathrm{NH}$ and $\mathrm{CN}$. Spatially resolved measurements have provided insight in the molecular emissions distributions along the spark gap, and revealed that besides the radicals of interest, other emission lines were present and could be identified as being mainly due to nickel, copper and iron lines originating from electrode wear. Results have shown that although a dependence of the intensity ratios of $\mathrm{CN}_{388} / \mathrm{OH}_{306}$ and $\mathrm{CN}_{388} / \mathrm{NH}_{336}$ on the fuel-air ratio was found, shot to shot repeatability was poor, thus suggesting further investigation on the atomic emission lines in order to further improve the technique. The present work is therefore an extension of the previous one.

The present work is based on the SIBS-based diagnostic tool developed by Kammermann et al. [36] for investigation of different quiescent mixture compositions at ambient temperature and elevated pressure conditions using a constant volume cell. Spectral emissions were analy zed in order to gather information on the local mixture composition around the spark plug. Atomic spectral emissions in different ambient conditions for methane/air mixtures were compared and discussed, with the aim to obtain a deeper insight on the SIBS response to the complex physical and chemical phenomena underly ing the ignition event. The objectives of this work were: 1 ) to perform an optimization of the gating strategy for atomic spectral emissions acquisition in methane/air mixtures, carefully considering the physics of the spark ignition; 2) to discuss the effect of pressure and temperature variations at constant density on the spectral features; 3 ) to discuss the effects of fuel-air equivalence ratio and pressure on the spectral emissions of quiescent methane/air mixtures, and 4) to tran sfer the proposed technique to a fiber-optic spark plug setup, which is the first step in running engine application of the proposed SIBS-based diagnostics.

This paper is organized as follows. In Section 2 (Experimental Methods), a description of the experimental test bench and of the two setups used is provided. The electrical discharge, the plasma features and the selected gating strategy are discussed, as well as the reasons for the approach used in this work. The emission lines, the operating parameters used and the data evaluation method are then described. In Section 3 (Results and discussion) the effects of varying pressure and temperature at constant density is evaluated. Then, fuel-air equivalence ratio and pressure on peaks intensity ratio and on peaks width are taken into account. Finally, the transfer of the proposed technique to a fiber optic spark plug is discussed, and the conclusive remarks are provided in Section 4.

\section{Experimental methods}

\subsection{Experimental setup}

A constant volume ignition cell, designed for optical investigation of emissions from sparks in homogeneous quiescent mixtures and coupled with a spectrometer was used. The cell is equipped with pneumatically actuated in- and outlet-valves, an absolute pressure sensor (Keller PAA-33X) for the control of the filling process and with a piezoelectric pressure transducer (Kistler 6052C) to measure 
the transient in-cell pressure during combustion. The filling of the cell was performed using an automation system which involves mass flow controllers (Bronkhorst) for a precise dosing. A detailed description of the setup can be found in [36].

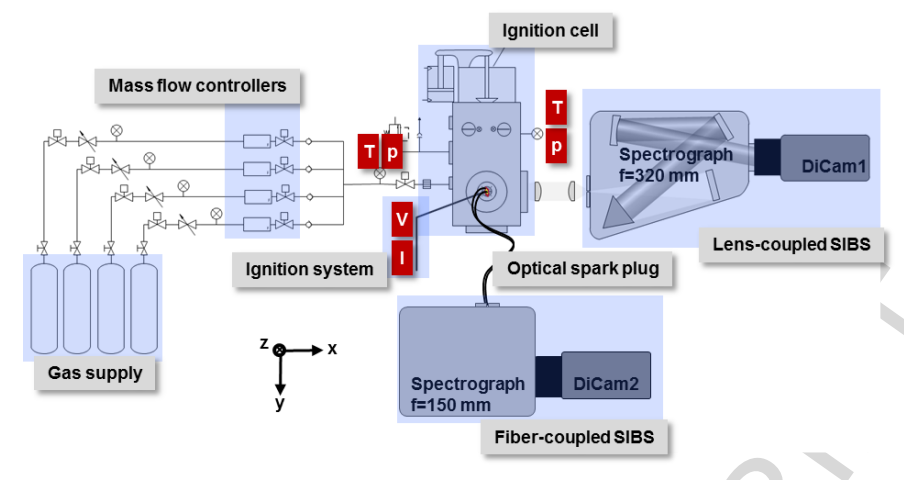

Figure 1: Sketch of the experimental setup for SIBS-based ignition diagnostics.

The ignition sy stem was based on a commercially available ignition coil (BERU), providing $60 \mathrm{~mJ}$ of energy with a maximum spark duration of $2.2 \mathrm{~ms}$ at $800 \mathrm{~V}$ Zener load, operated at a dwell time of $2 \mathrm{~ms}$. The coil was mounted on astandard optical M1o thread spark plug (NGK) with double fine wire electrodes and an electrode gap of $1 \mathrm{~mm}$. Secondary voltage and current signals were measured via a high voltage probe (Tektronix P6015A) and a fast current monitor (Pearson Model 6585) on an oscilloscope with $1 \mathrm{GHz}$ bandwidth (LeCroy Wavesurfer 10). Additionally, the secondary current signal was used to trigger the intensified cameras.

\subsection{Lens setup}

The light emitted by the spark plasma was collected via a lens system through sapphire windows and transferred to the spectrometer slit. A slit width of $50 \mu \mathrm{m}$ and a $400 \mathrm{~nm}$ cut-on filter was used throughout this study. Wavelength calibration spectra were captured from a mercury neon lamp. A grating of $300 \mathrm{~mm}^{-1}$ was used on the Princeton Instruments spectrograph (Acton IsoPlane SCT 320) with a focal length of $320 \mathrm{~mm}$. An intensified CCD camera (PCO DiCam Pro) with a detector size of $1280 \times 160$ pixels was used to collect the spectra, with a resulting spectral resolution of $1.3 \mathrm{~nm}$.

\subsection{Fiberoptic sparkplug setup}

In this setup, the light emitted by the plasma was collected using two sapphire rods embedded in a housing attached to the left and right of the ground electrode hook, coupled to an optical fiber and guided to the spectrometer. The light emitted by the plasma was collected by the sapphire rod with a chamfered end, so that the viewing conewas pointing towards the electrode gap as illustrated in Figure 2. Solarization-resistant optical fibers were coupled to the sapphire rod to guide the emitted light to a Spectra Pro 150 spectrometer with a focal length of $150 \mathrm{~mm}$. A slit width of $150 \mu \mathrm{m}$, a $400 \mathrm{~nm}$ cut-on filter and a grating of $600 \mathrm{~mm}^{-1}$ were used. A second intensified PCO DiCam Pro camera with a detector size of $1280 \times 128$ pixels was used for the fiber setup. The spectral resolution for this setup is $1.56 \mathrm{~nm}$ for the $600 \mathrm{~mm}^{-1}$ grating. Figure 2 illustrates the position of the fiber and the corresponding viewing cone (red) together with the viewing cone from the lens setup (green). 


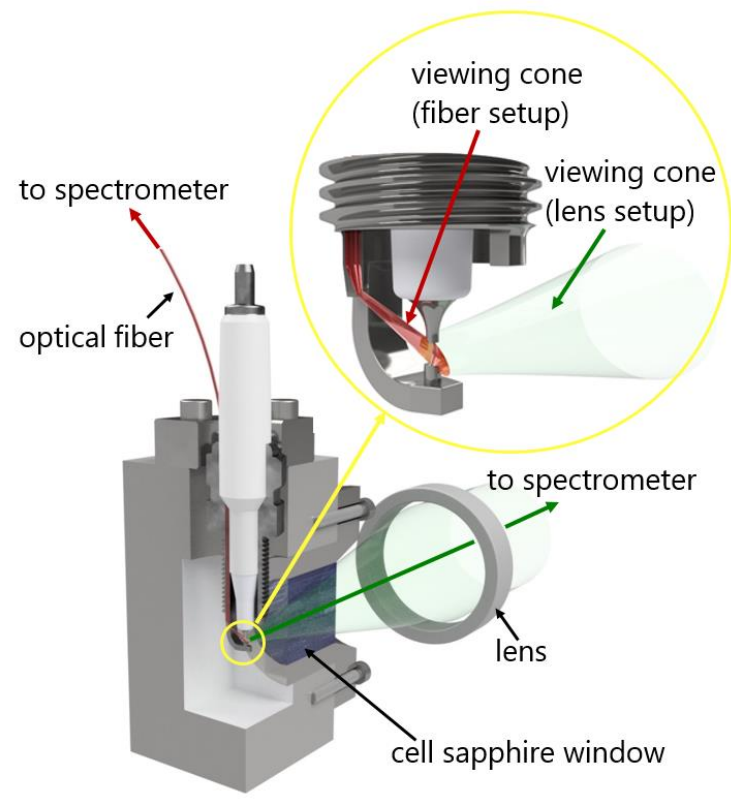

Figure 2: Sketch of the two light collection setups used in this work: the lens setup, where the emission from the plasma is collected by a lens (green cone) and the fiber setup, where the emitted light is collected by a chamfered sapphire rod embedded in the spark plug (red cone).

\subsection{Electrical discharge}

The spark discharge process can be divided into three phases: breakdown-, arc-, and glow-discharge. During the breakdown phase, a highly conductive plasma channel is formed between the spark electrodes. Molecules in the plasma channel are dissociated and ionized with a high plasma temperature of up to tens of thousands $\mathrm{K}$ [29]. This plasma temperature then decreases due to cooling, radiation and recombination phenomena. Ionization and dissociation energy are transformed into thermal energy during plasma cooling. In the arc phase, the thin cylindrical plasma expands due to heat conduction and heat diffusion [34]. Due to these energy transfers and due to radiative transfer, the plasma temperature in the arc decreases, and a lower degree of ionization is present. Following the arc phase, a glow discharge can be formed and maintained for several milliseconds due to the secondary coil in a conventional coil spark-ignition system. The glow discharge has lower power but transfers more energy due to the long discharge time. Inside the plasma channel, the combustible mixture is preheated up to the adiabatic flame temperature. Chemical reactions are initiated by the high radical density region in the breakdown phase; after several tens of microseconds, the plasma temperature decreases to values comparable to the adiabatic flame temperature. Recombinations to form radicals such as $\mathrm{OH}, \mathrm{NH}, \mathrm{CN}$ and $\mathrm{CH}$ take place and that can be observed as spectral emissions starting some microseconds after the breakdown.

The interaction of the electrical discharge with its environment strongly affects the spectral emissions from the plasma, as discussed in the introduction. As a consequence, the gating strategy for measurement acquisition must be carefully selected. In particular, the delay from breakdown $\left(t_{d}\right)$ and the exposure time $\left(t_{e}\right)$ need to be adjusted depending on the desired measurements, for example at shorter delays the atomic emissions are more likely to be visible, while molecular emissions tend to be 
visible at later times. Moreover, restrike phenomena can affect the overall measured emissions. In order to avoid strong continuum emissions, it is therefore important to select the exposure time in such a way that restrikes are not included in the measurement. Additionally, restrike phenomena can occur randomly in subsequent measurement repetitions, so a careful selection of valid spectra which display a good peak to continuum ratio is needed. The continuum level was the criterion used in this work to determine the selected spectra.

Another parameter affecting the electrical discharge is the operating pressure. In
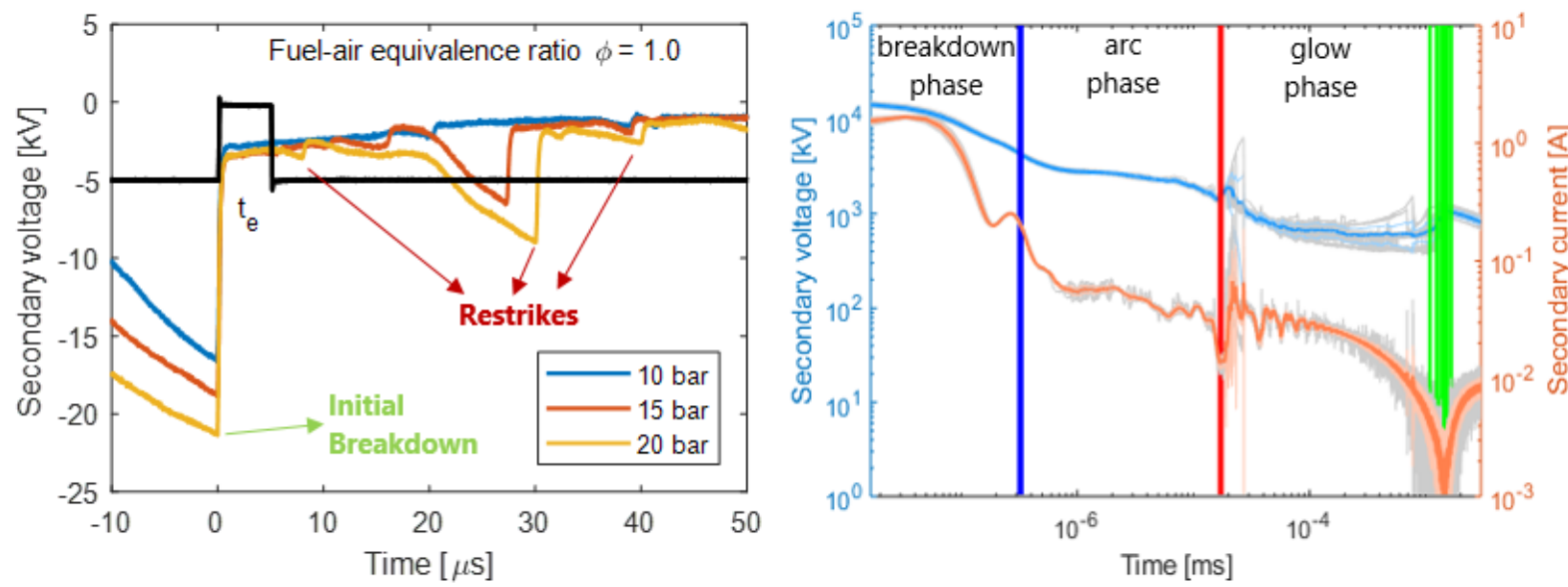

Figure 3 (left plot) the typical secondary voltage signals are shown for the different pressure values investigated, at stoichiometric conditions. Although the discharges take place in a quiescent mix ture, it can be noticed that restrikes (rises in secondary voltage) can be observed starting already from approximately $10 \mu \mathrm{s}$ after breakdown, and more prominently around $30 \mu \mathrm{s}$. The intensity of the restrikes rises with increasing pressure, thus suggesting that an effective gating strategy must consider this phenomenon in order to avoid superposed continuum emission in the spectral response. Figure 3 (right plot) also shows the secondary current and secondary voltage curves for a ty pical test, at 10 bar. These curves are shown on a log-log plot in order to highlight the different time scales for the breakdown-, arc- and glow-phases of the electrical discharge.
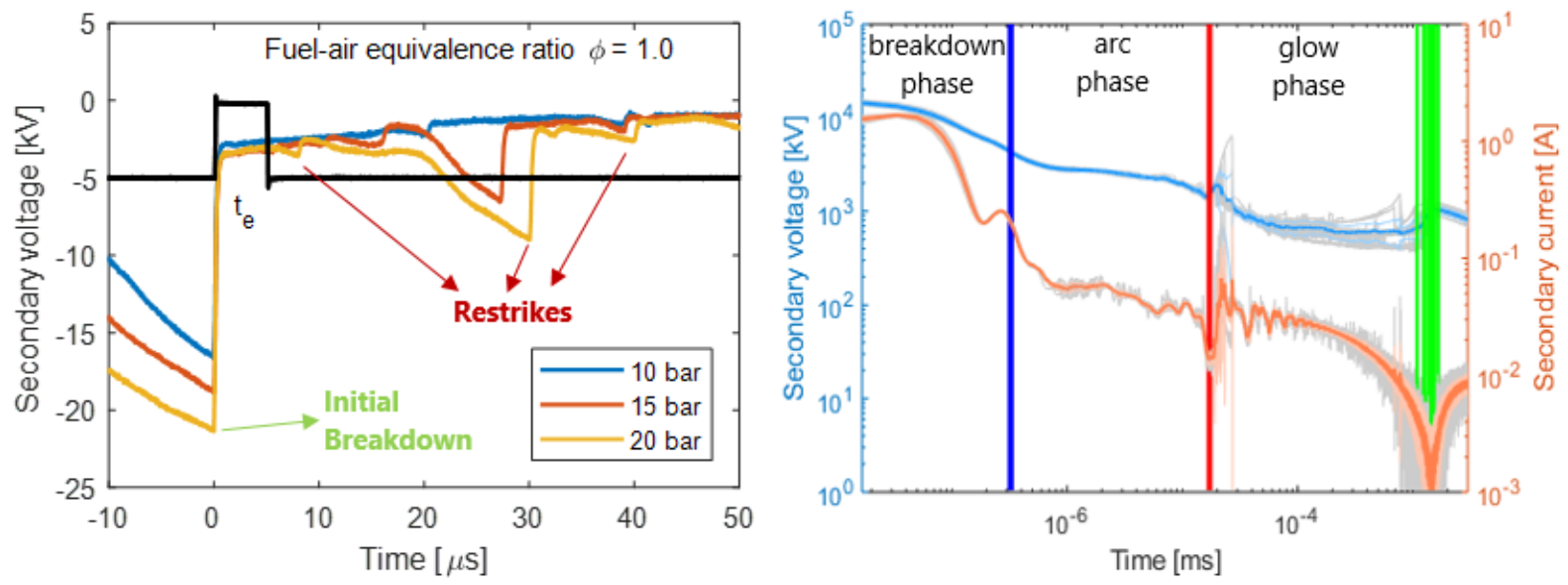

Figure 3: Left: breakdown voltage and camera gating signals for different pressure levels at ignition time. Restrike phenomena are visible as sharp rises in secondary voltage. Right: secondary current and voltage curves vs. time. The breakdown-, arc-and glow-phases are highlighted.

A trigger device was used in this work to trigger the intensified CCD camera after the breakdown 
phase, using the secondary current as trigger input. The output signal of the comparator had an intrinsic delay of $50 \mathrm{~ns}$ with respect to the breakdown. In the present work the camera was gated immediately after breakdown with an exposure time of $5 \mu \mathrm{s}$, while the measured duration of the inductive discharge was $1.3 \mathrm{~ms}$. The breakdown duration is approximately $200 \mathrm{~ns}$.

\subsection{Plasma characterization}

Energy transfer from the spark plasma to the combustible mixture is the key phenomenon to form a stable initial flame kernel. The efficiency of this thermal energy transfer is strongly affected by the plasma temperature and electron density, which influence the dissociation, atomization, ionization, and excitation processes occurring in the plasma [30,37]. Knowledge of such plasma characteristics is therefore of great interest for combustion processes understanding and control. Nevertheless, due to the complex phenomena involved and to difficulties in isolating the different effects, it is often a challenging task [30,38-41]. In the present work, the focus was on relating the peaks intensity ratios and the peak widths to the fuel-air equivalence ratio in the vicinity of the spark plug, in engine relevant conditions. In order to assess the feasibility of the selected approach, a preliminary study was performed, carefully considering the physical phenomena involved in the spark-induced breakdown. Because of the transient nature of the spark-induced plasma, the atomic and ionic populations rapidly evolve with time and position. As a consequence, the spectra emitted by the plasmas vary significantly, depending upon the observation time after the breakdown. At short times $(<500 \mathrm{~ns})$ the plasma emission consists of an intense continuum that decreases with time. At later times, emission lines due to the radiative decay of excited species dominate the radiation process as the plasma cools and expands, so the ionized lines gradually disappear and are replaced by emission from excited neutral atoms [40]. The gating strategy used in the present work and discussed in Section 2.4 ensures a proper selection of the measurements timing, optimizing the signal to noise ratio for the emissions of interest. The spectral lines considered in the present work are reported in Table 1, together with the relevant atomic data [42]. Energy levels (E) and transition probabilities ( $\mathrm{A}_{\mathrm{ki}}$ ) are shown.

\begin{tabular}{llll}
$\begin{array}{l}\text { Atomic } \\
\text { lines }\end{array}$ & $\begin{array}{l}\text { Wavelength } \\
(\mathbf{n m})\end{array}$ & $\mathbf{E}_{\mathbf{i}}\left(\mathbf{c m}^{-1}\right)-\mathbf{E}_{\mathbf{k}}\left(\mathbf{c m}^{-1}\right)$ & $\mathbf{A}_{\mathbf{k i}}\left(\mathbf{s}^{-1}\right)$ \\
\hline $\mathbf{H}_{\alpha}$ & 656.28 & $82259.28-97492.35$ & $6.46 \times 10^{07}$ \\
$\mathbf{O}_{777}$ & 777.19 & $73768.20-86631.45$ & $3.69 \times 10^{07}$ \\
$\mathbf{O}_{777}$ & 777.41 & $73768.20-86627.77$ & $3.69 \times 10^{\circ 7}$ \\
$\mathbf{O}_{777}$ & 777.53 & $73768.20-86628.75$ & $3.69 \times 10^{07}$ \\
$\mathbf{N}_{742}$ & 742.36 & $83284.07-96750.84$ & $5.95 \times 10^{07}$ \\
$\mathbf{N}_{744}$ & 744.22 & $83317.83-96750.84$ & $1.24 \times 10^{07}$ \\
$\mathbf{N}_{746}$ & 746.83 & $83364.62-96750.84$ & $1.93 \times 10^{07}$ \\
\hline Table 1: Relevant atomic data for the observed spectral lines [42].
\end{tabular}

The use of line shapes for inhomogeneous plasma diagnostics is a very difficult task, in particular when a strong gradient of electron density and plasma temperature is present. In this case the line profile is distorted by superposition of line radiation from cooler plasma layers onto the line profile from the central hot part of the plasma. Then, instead of expected typical self-absorbed broadened profile one may get the resulting overall profile with smaller half width and/or distorte d due to difference in line 
shifting in hot dense plasma and cold layer and the distorted profiles cannot be used for plasma diagnostics without plasma modeling to fit ex perimental line shape [43]. In the conditions investigated in the present work, these effects are negligible compared to the overall observed broadening, and are therefore not taken into account.

The presence of self-absorption, resulting from nearby species in their ground state which absorb resonantly the radiation propagating through the space, can also cause distortion of spectral profiles. In case of self-absorption, the central part of line profile (largest radiation intensity) is absorbed the most by the same species in the lower energy state of transition and the maximum of line profile decreases while relative line width increases if collisional de-excitation is present [43]. It is worth noticing that the presence of self-absorption can limit the range of operating pressure and lead to erroneous results in the spectral line ratios. Nevertheless, the focus of the present work is on the comparison of the ratios between corresponding spectral features, and in particular on the identification of the trends between these ratios and the gas mix ture conditions (fuel-air equivalence ratio and pressure) using two different measurement setups. Since self-absorption effects are the same in both setups measurements, they are not further considered in the present work.

\subsection{Operating parameters}

The operating conditions used in this work are shown in Table 2 and Table 3.

\begin{tabular}{lllll}
$\begin{array}{l}\text { Test } \\
\text { condition }\end{array}$ & $\begin{array}{l}\text { T } \\
(\mathbf{K})\end{array}$ & $\begin{array}{l}\mathbf{p} \\
\text { (bar) }\end{array}$ & $\begin{array}{l}\boldsymbol{\phi} \\
(-)\end{array}$ & $\begin{array}{l}\text { Density } \\
(\mathbf{k g} / \mathbf{m} \mathbf{3})\end{array}$ \\
\hline $\mathbf{a}$ & 293 & 10 & 2.5 & 10.8 \\
& & & 0.4 & 11.6 \\
$\mathbf{b}$ & 365 & 12.5 & 2.5 & 10.8 \\
c & & & 0.4 & 11.6 \\
& 440 & 15 & 2.5 & 10.8 \\
\hline
\end{tabular}

Table 2: Operating conditions for two different densities at varying temperature and pressure levels.

Tests were performed using premixed methane/air mixtures at fuel-air equivalence ratios $(\phi)$ ranging from 0.4 to 2.5. The operating pressure and temperature werevaried in the range $10-20$ bar and 293$440 \mathrm{~K}$, respectively. This results in gas densities at spark timing which are in the relevant medium- to high load range for spark ignition engines.

\begin{tabular}{lllll}
$\begin{array}{l}\text { Test } \\
\text { condition }\end{array}$ & $\mathbf{T}$ & $\mathbf{p}$ & $\boldsymbol{\varphi}$ & $\begin{array}{l}\text { Density } \\
(\mathbf{k g} / \mathbf{m} 3)\end{array}$ \\
\hline $\mathbf{1}$ & 293 & 10 & $0.4-2.5$ & $10.8-11.6$ \\
$\mathbf{2}$ & 293 & 15 & $0.4-2.5$ & $16.1-17.4$ \\
$\mathbf{3}$ & 293 & 20 & $0.4-2.5$ & $21.5-23.3$ \\
\hline \multicolumn{4}{r}{ Table 3. Operating conditions for pressure variations. }
\end{tabular}

\subsection{Data evaluation}

The gating strategy must be carefully selected, depending on the targeted spectral emissions. Namely, 
triggering for a short time (some microseconds) after breakdown allows measuring atomic em issions, while molecular emissions tend to appear at a later time, as discussed in Section 2.4, and therefore require delayed or longer ex posure time. For this reason, in [36] an exposure time of $2 \mathrm{~ms}$ was used to measure molecular emissions, while for the present investigation a shorter exposure time was set, based on preliminary tests performed to assess the optimal choice. The selected strategy for the present investigation includes an exposure time of $5 \mu$ s and a delay of zero, i.e. the acquisition is triggered immediately after the breakdown. This ensures only atomic emissions are measured. The emission lines evaluated for the tests performed in this work are $\mathrm{H}_{\alpha}(656 \mathrm{~nm}), \mathrm{N}(742-746 \mathrm{~nm})$ and $\mathrm{O}$ (triplet at $777 \mathrm{~nm}$ ), as listed in Table 1.

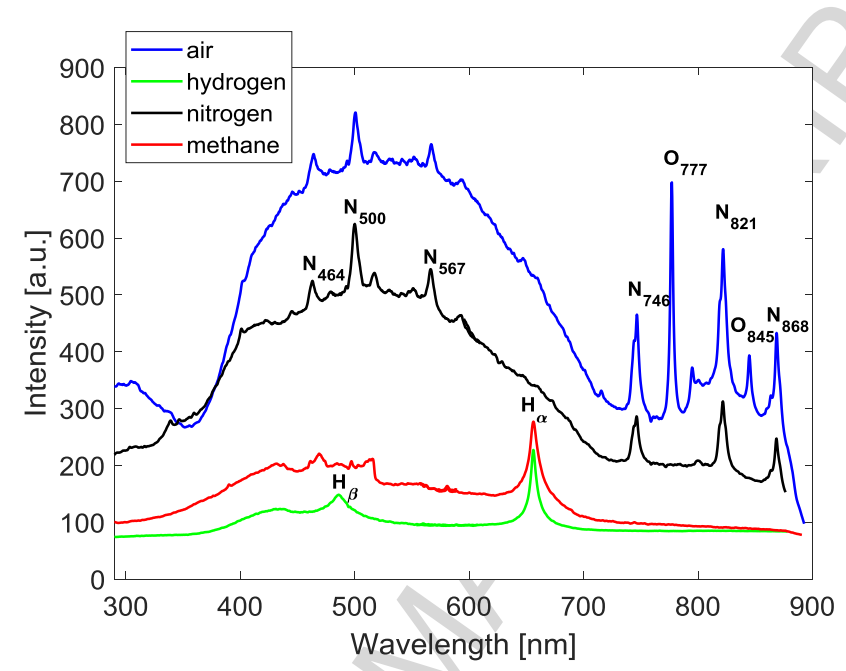

Figure 4. Spectra with indicated emission lines.

Figure 4 shows individual spectral emissions obtained from air, hydrogen, nitrogen and methane. The atomic lines of interest, corresponding to the hydrogen Balmer- $\alpha$ line at $656 \mathrm{~nm}\left(\mathrm{H}_{\alpha}\right)$, the oxygen line at $777 \mathrm{~nm}\left(\mathrm{O}_{777}\right)$, and the most prominent nitrogen lines (including $\mathrm{N}_{746}$ ) are also indicated. High continuum emissions are measured for air and nitrogen, while this feature is notably lower when methane and hydrogen are taken into account. Moreover, methane emission displays weak peaks between 450 and $550 \mathrm{~nm}$, corresponding to the $\mathrm{C}_{2}$ Swan bands. In the hydrogen spectrum, the two lines corresponding to Balmer- $\alpha(656 \mathrm{~nm})$ and $\beta(486 \mathrm{~nm})$ lines are identified.

An example of ty pical methane/air mix ture spectra acquired at zero delay time and $5 \mu$ s exposure time is shown in Figure 5. When a methane/air mixture spectral signature is recorded at the same conditions as those used for puregases, the atomic lines corresponding to $\mathrm{H}_{a}, \mathrm{O}_{777}$ and $\mathrm{N}_{746}$ can still be clearly recognized (Figure 5), although the other distinctive features are not present any more. When the mixture spectrum is analyzed, the carbon contribution found in the Swan bands and originating from methane cannotbe observed anymore. The emission lines from $\mathrm{H}_{a}, \mathrm{~N}_{746}$ and $\mathrm{O}_{777}$, clearly visible in the spectra, will be used for quantitative characterization of local fuel air equivalence ratio. The atomic ratios of these lines will be indicated in the following as $\mathrm{H} / \mathrm{O}$ and $\mathrm{H} / \mathrm{N}$.

Figure 5 also visualizes the data evaluation strategy. For the lens setup, the spectrum is resolved along the electrodegap. Since the spatial information cannotbe reconstructed in the fiber setup, only spectra averaged along the gap were considered. Additionally, on each spectrum a subtraction of the background and a baseline correction were performed as illustrated in Figure 5. For each spectrum, 
the background was corrected by subtracting the dark signal from the camera. The baseline was defined in order to obtain a consistent procedure for measuring all peaks intensity and width. Namely, since different spectra (or different repetitions of the same spectra) may display different continuum emissions intensities, the "zero" of the spectrum may be shifted to non-zero intensity values, thus leading to erroneous evaluation of peaks intensity and width. In order to avoid this error, a bas eline was defined for each spectrum by considering the "zero emission"intensity in a range of $10 \mathrm{~nm}$ before and after each peak. A quadratic fitting was applied in order to define the spectral baseline (i.e. the spectrum in the considered wavelength range without the peak), and this curve was taken as the baseline for the considered peak. This procedure ensures that all peak intensities and peak widths were evaluated consistently, avoiding the effect of different continuum emission intensities for different experimental conditions (as discussed in Sections 2.4 and 2.5). Each peak intensity was therefore evaluated from its spectral baseline. The Full Width at Half Maximum (FWHM) was used to evaluate the peak width.

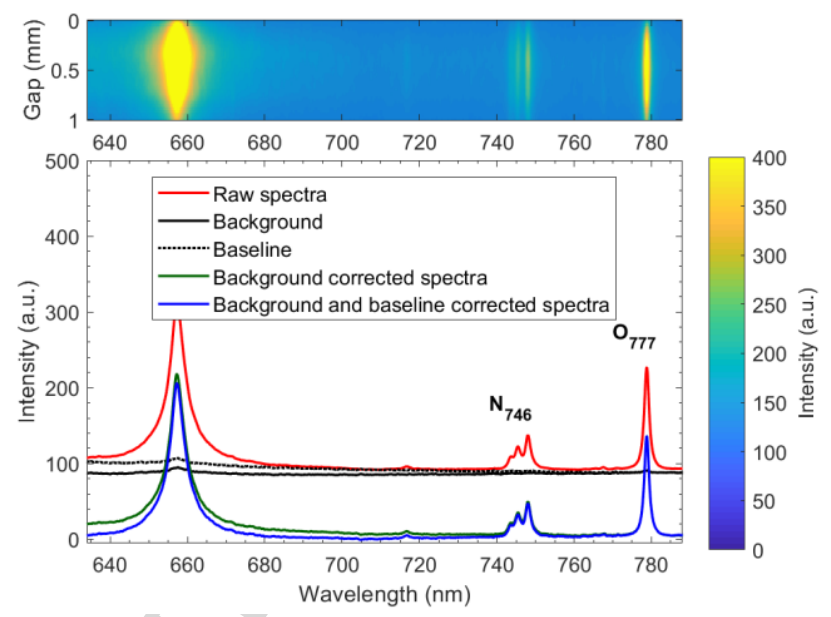

Figure 5. Spatially resolved spectrum of a stoichiometric methane-air mixture and spatially averaged spectrum with illustrated background and baseline correction.

Each test was performed by acquiring 20 repetitions; therefore an average over 20 spectra is obtained, unless otherwise stated.

\section{Results and discussion}

The spectral emissions obtained from methane/air mixtures are discussed at different experimental conditions. First, the effect of changing the mixture pressure and temperature while keeping the density constant is discussed; then, the effect of fuel-air equivalence ratio on spectral emissions is considered, and finally the role of pressure is reviewed.

\subsection{Effect ofdensity}

Since the plasma temperature, as discussed in Section 2.5, is by about one order of magnitude higher than the ty pical adiabatic flame temperature, one can expect that the pressure of the mixture is an important parameter affecting the spectral emissions. Conversely, different temperature and pressure combinations for the same density should not change the emission characteristics. Before considering the effect of pressure on spectral measurements, preliminary tests were carried out with the aim to 
verify this assumption, taking into account the link between pressure, temperature and density, as described in this Section.

The spectral emissions obtained at different values of the fuel-air equivalence ratio are plotted in Figure 6 for ambient pressure values of 10, 15 and 20 bar, at ambient temperature (293 K).
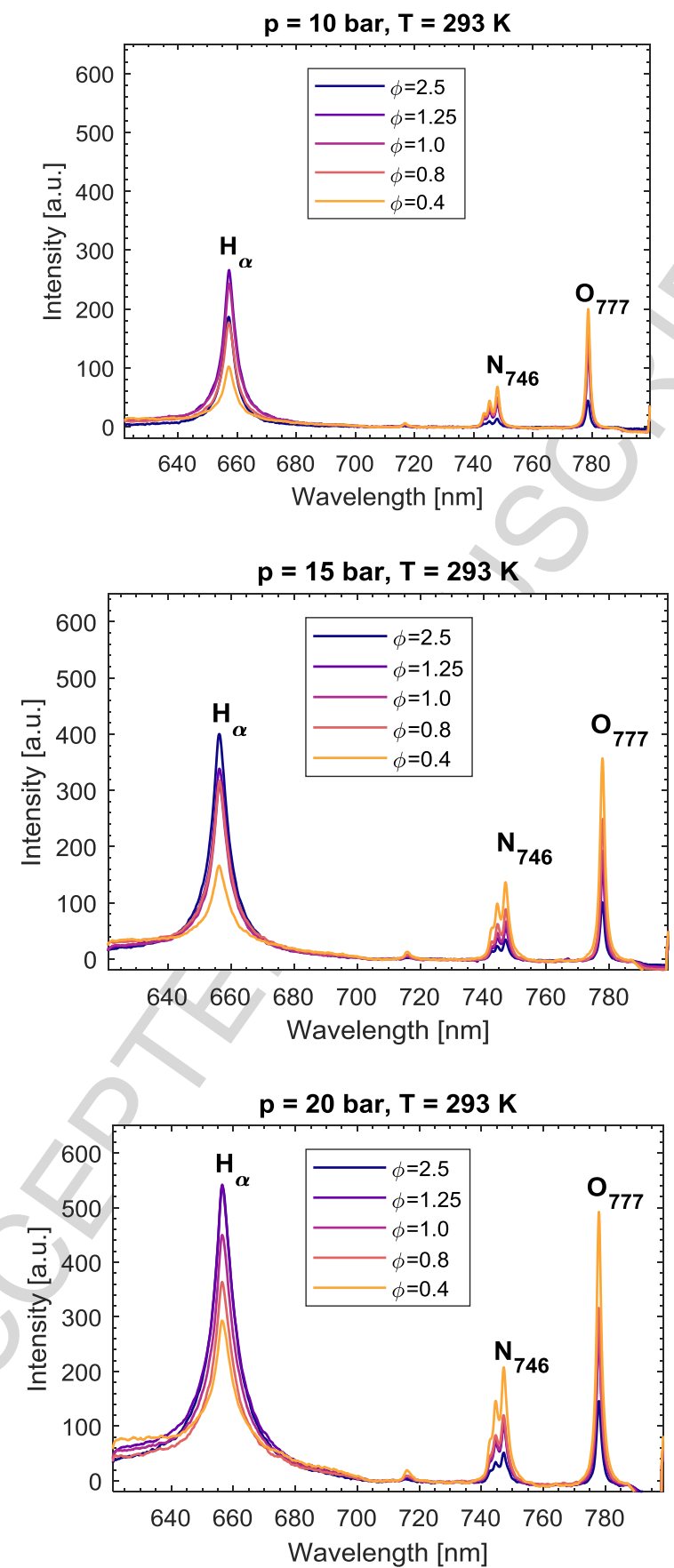

Figure 6: Spectral emissions vs. fuel-air equivalence ratio and pressure at $293 \mathrm{~K}$.

For all cases, the peaks intensities tend to follow the expected trend: namely, the oxygen peak steadily increases for increasing air content, while the hydrogen peak decreases. When fuel-rich mixtures are considered, an unex pected behavior is observed. Namely, the hydrogen peak does not further increase when increasing $\phi$ from 1.25 to 2.5 . This might be due to self-absorption effects. It is worth noticing that for very fuel-lean mixtures $(\phi<0.4)$, the hydrogen peak becomes too weak to allow for 
quantitative evaluation; conversely, for very fuel-rich conditions ( $\phi \geq 2.5$ ), both nitrogen and oxygen peaks become barely recognizable. Therefore, for all the tests reported in this paper, quantitative evaluation of spectral features has been carried out in the range $0.4 \leq \phi \leq 2.5$, if not otherwise stated. Comparing the plots shown in Figure 6, it can be noticed that for increasing ambient pressure, the spectral emissions tend to be more prominent, for all the species investigated.

In order to gain a better insight of the role of operating parameters in determining the spectral emissions features, an investigation was performed to assess the separate contribution of pressure, temperature and fuel-air equivalence ratio on the overall spectral response. A series of tests was carried out in which the operating pressure and temperature were changed while keeping the corresponding density constant, as shown in Table 2.

The atomic ratios ( $\mathrm{H} / \mathrm{O}$ and $\mathrm{H} / \mathrm{N})$ for the spectra obtained in test conditions $\mathrm{a}), \mathrm{b})$ and $\mathrm{c}$ ) were calculated, and are reported in Figure 7 and in Figure 8, respectively. The error bar represents the standard deviation over 20 repetitions.

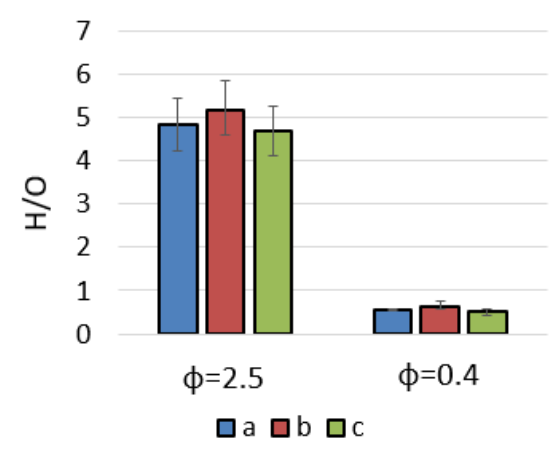

Figure 7: $\mathrm{H} / \mathrm{O}$ ratio at different mixture densities for the tests reported in Table 2: $a(p=$ $10 \mathrm{bar}, T=293 \mathrm{~K}), \mathrm{b}(p=12.5 \mathrm{bar}, T=365 \mathrm{~K})$, and $c(p=15$ bar, $T=440 \mathrm{~K})$.

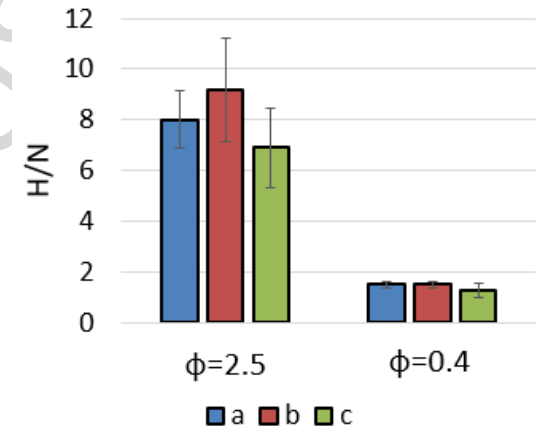

Figure 8: $H / N$ ratio at different mixture densities for the tests reported in Table 2: a ( $p$ = 1obar, $T=293 \mathrm{~K}), b(p=12.5 \mathrm{bar}, T=365 \mathrm{~K})$, and $c(p=15$ bar, $T=440 \mathrm{~K})$.

When the three test conditions a), b) and c) are compared, both ato mic ratios display a constant value within the experimental uncertainty. This proves that different pressure and temperature combinations do not result in changes in the atomic peak ratios, as long as the corresponding density is kept constant. Comparing Figure 7 and Figure 8, it can be seen that for the fuel-richer condition $(\phi=2.5)$, the $\mathrm{H} / \mathrm{O}$ value is around 4.9 , while the $\mathrm{H} / \mathrm{N}$ value is approximately 8 . For the fuel-leaner case, lower peaks intensity ratios are obtained (0.58 and 1.42, respectively). For both ratios, higher standard deviations are obtained for $\phi=2.5$ : this is mainly due to the lower signal level for oxygen and nitrogen at fuel-richer conditions.

\subsection{Effect of fuel-air equivalence ratio}

The impact of the fuel-air equivalence ratio variation on spectral emissions for constant operating pressure and temperature was investigated, both in terms of peaks intensity ratios and peaks broadening. In these tests, operating temperature is set at $\mathrm{T}=293 \mathrm{~K}$, while $\phi$ ranges from 0.4 to 2.5 and pressure from 10 to 20 bar as shown in Table 3. Figure 9 shows an example of typical spectral 
emissions obtained at $\mathrm{p}=10 \mathrm{bar}$, for three different values of fuel-air equivalence ratio. Similar results (not reported here) were obtained for lower pressures and other $\phi$ values investigated. The results presented in this section were obtained acquiring 20 repetitions for each spectrum.

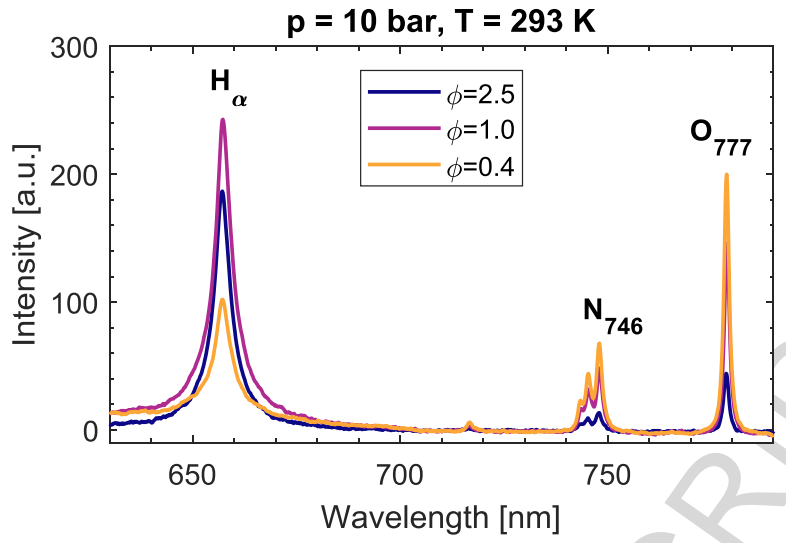

Figure 9: Spectral emissions for different air to fuel ratios, at pressure $p=10$ bar.

Peak intensity ratios were calculated based on the obtained spectral responses. Both $\mathrm{H} / \mathrm{O}$ and $\mathrm{H} / \mathrm{N}$ intensity ratios linearly increase for increasing $\phi$, i.e. for fuel-richer mixtures. Results are shown in Figure 10 for the $\mathrm{p}=10$ bar case.

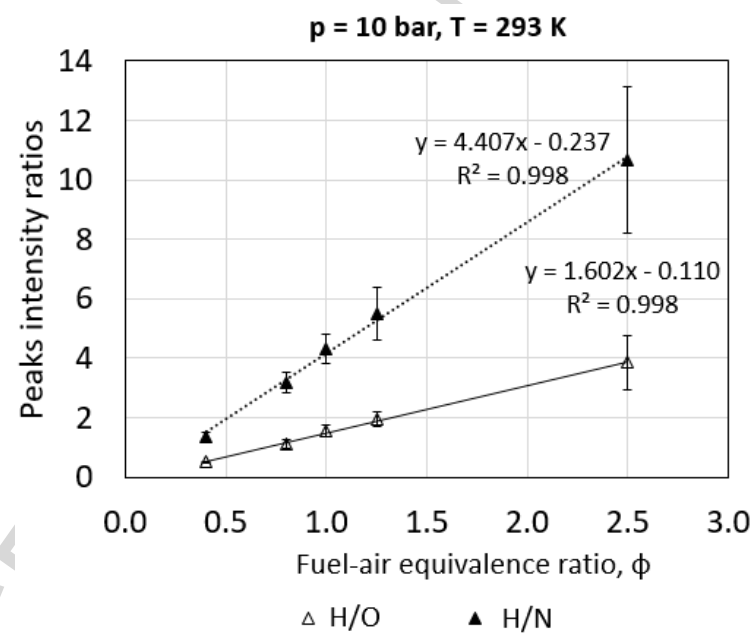

Figure 10: Peaks intensity ratios vs. fuel-air equivalence ratio, at pressure $p=10$ bar.

The measurements uncertainty is higher for fuel-richer cases, ranging from 0.04 for $\phi=0.4$ to 0.91 for $\phi=2.5$ when $\mathrm{H} / \mathrm{O}$ is considered, and from 0.14 to 2.46 , respectively, when $\mathrm{H} / \mathrm{N}$ is taken into account. This corresponds to a percentage error ranging from $7 \%(\mathrm{H} / \mathrm{O})$ and $10 \%(\mathrm{H} / \mathrm{N})$ in the best case, up to $23 \%$ for both ratios in the worst case. On the one hand, the higher uncertainty in fuel-richer conditions can be explained taking into account the higher difficulty in peaks identification when the signals become weaker. On the other hand, the higher uncertainty generally obtained when considering $\mathrm{H} / \mathrm{N}$ ratio can be explained considering the lower overall prominence of the nitrogen peak when compared to $\mathrm{O}$ and $\mathrm{H}$, which results in increased difficulty in properly resolving the peak under less favorable conditions.

When the Full Width at Half Maximum (FWHM) is taken into account, it can be noticed that the hy drogen peak slightly broadens with increasingly fuel-lean mix tures (Figure 11), while the measured 
width for nitrogen and oxygen peaks tends to remain constant over the whole range investigated.

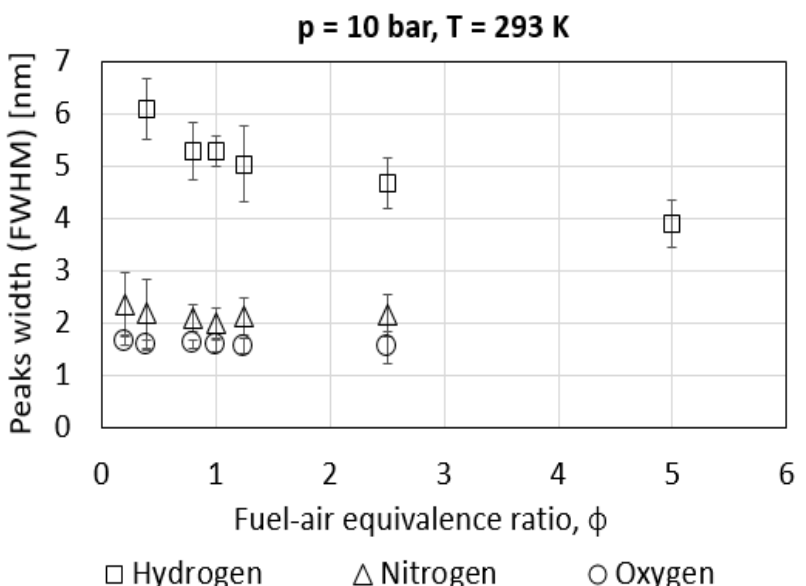

Figure 11: Peaks width (FWHM) vs. fuel-air equivalence ratio at $10 \mathrm{bar}$.

Examining Figure 11, it is worth noticing that the hydrogen peak was resolved in the range $0.4<\varphi<5$, while nitrogen and oxygen peaks disappear for $\varphi>2.5$, and are therefore not shown in the Figure. Moreover, both the nitrogen emission and oxygen peaks shown here consist of multiple lines. For nitrogen these are the $742.36,744.23$ and $746.83 \mathrm{~nm}$ lines and for oxygen the $777.19,777.42$ and $777.54 \mathrm{~nm}$ lines, respectively.

\subsection{Effect of pressure variation}

The impact of operating pressure variation on spectral emissions for constant fuel-air equivalence ratio and constant temperature was inv estigated. The spectral response for three different pressure values at stoichiometric mixture conditions is shown in Figure 12. In this case, the spectra obtained suggest that the change in pressure do not result in peaks intensity variation, while the peak broadening is apparent.

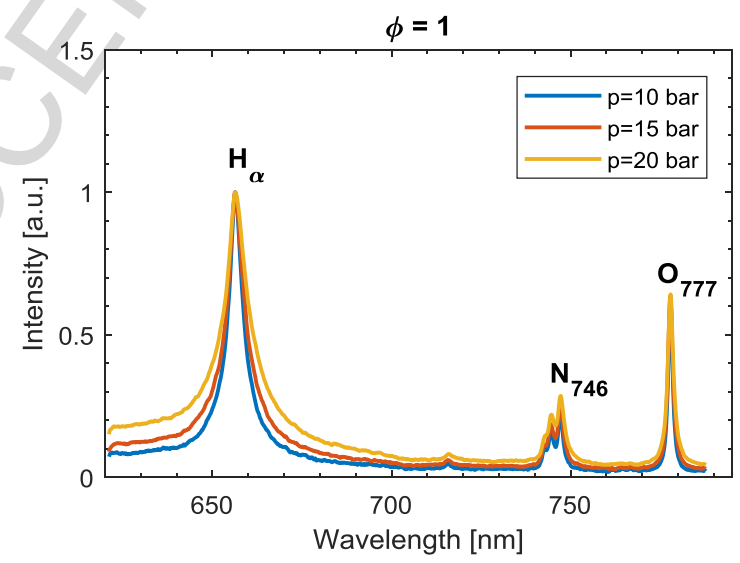

Figure 12: Spectra for different pressure values at stoichiometric mixture conditions, normalized to $H_{\alpha}$ peak value.

In order to quantitatively assess this result, tests were performed at different pressure values, for $\mathrm{T}=293 \mathrm{~K}$, and for fuel-air equivalence ratio ranging from 0.4 to 2.5 , as summarized in Table 3 . For each test conditions, 20 repetitions were acquired. 
If the peaks intensity ratios are plotted versus the fuel-air equivalence ratios, a linear trend is obtained for all the cases investigated, as shown in Figure 13 and in Figure 14 for H/O and H/N ratios, respectively.

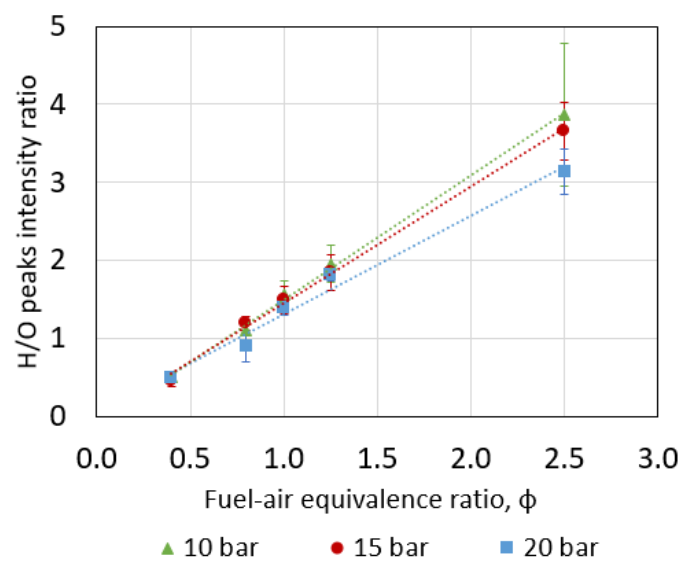

Figure 13: H/O intensity ratio vs. fuel-air equivalence ratio, at different pressure values.

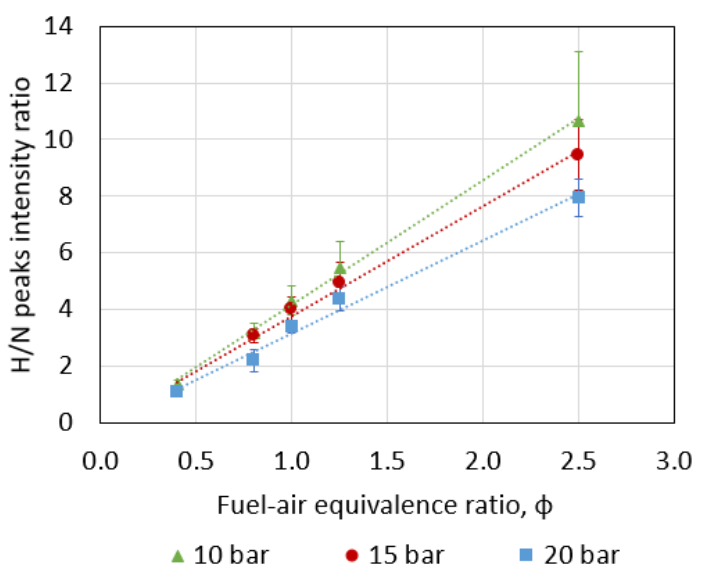

Figure 14: H/Nintensity ratio $v$ s. fuel to air, at different pressure values.

It is worth noticing that a slight decrease in the intensity ratios is observed at fuel-rich conditions, for higher pressure values. These results are consistent with those reported by Joshi et. al. in [25].

The corresponding standard deviation of the acquired spectra is also reported in the Figures, showing that higher uncertainty is obtained for higher $\phi$ values, for the same reason as discussed in the previous section. The fuel-air equivalence ratio can thus be estimated from the measured peaks intensity ratio, and it can be concluded that pressure has a minor effect on the results in lean conditions, but should be taken into account for fuel-rich conditions.

When the peak broadening is taken into account, a different behavior is observed with pressure variation. For all the atomic peaks investigated, a fairly linear increase in FWHM is obtained for increasing pressure, as shown in Figure 15 for $\phi=0.4$. Main reason for the line broadening is the reduced lifetime of the radiation process due to collisions. For increasing pressure, also the density and therefore the number of collisions increase, causing a premature transitions and emissions of photons. Conversely, if other broadening mechanisms, such as thermal and Doppler broadening, are of minor importance, the measured line width can be used as an estimate for the pressure. 


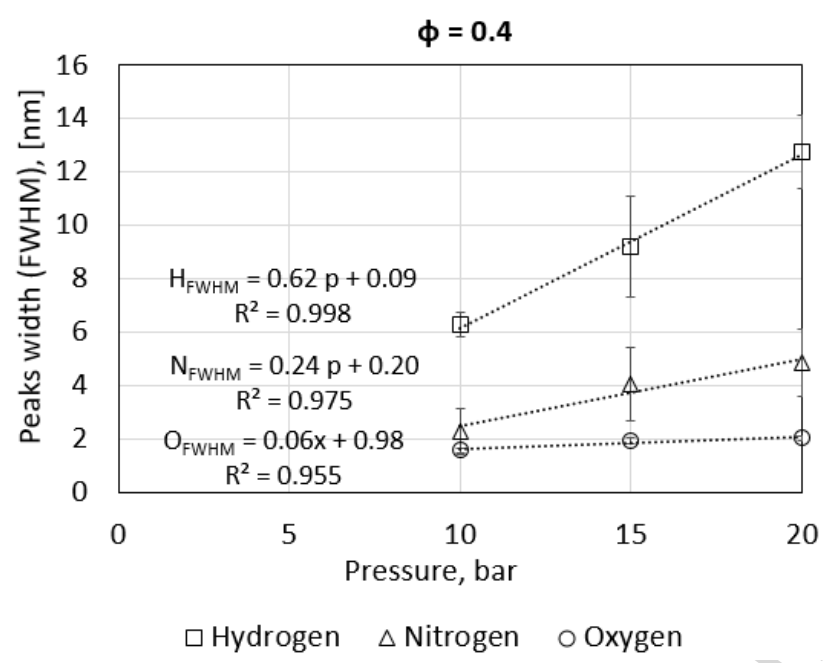

Figure 15: Peaks width (FWHM) vs. pressure, trends for $\phi=0.4$.

From the results presented in this section, it can be concluded that the local fuel-air equivalence ratio in the vicinity of the spark plug depends linearly on the intensity ratios $\mathrm{H} / \mathrm{O}$ and $\mathrm{H} / \mathrm{N}$ with a slight dependency on the density, especially towards fuel-rich conditions. The broadening of the atomic emission lines of $\mathrm{H}_{\alpha}, \mathrm{O}_{777}$ and $\mathrm{N}_{746}$ could be used as an estimate of the density and therefore as a direct correction factor for the above mentioned density dependence.

\subsection{Transfer to fiber-optic sparkplug}

In order to use the proposed diagnostic technique for engine applications, including pre-chamber applications as in $[16,44]$, the plasma emissions cannot any longer be collected via lenses or mirrors. Therefore, the optical spark plug, as described in section 2.3, was mounted in the constant volume cell to simultaneously acquire an additional spectrum via the fibers to compare with the existing lens setup.

The results summarized in the previous sections were compared to the measurements acquired using the fiber setup during the same tests, in order to assess the feasibility of this method for future engine applications. Figure 16 shows the acquired signals from the same tests reported in Figure 6a, at $p=10$ bar, $\mathrm{T}=293 \mathrm{~K}$, for fuel-air equivalence ratios ranging from 0.4 to 2.5 . It can be seen that the general trends in spectral response are the same for both setups, even if the signals acquired from the fiber setup are weaker compared to those obtained from the lens setup. Moreover, the spatial resolution along the electrode gap of the lens setup is lost in the fiber setup. Also in this case, it can be noticed that increasing the $\phi$ value results in decreased hydrogen peak intensity only up to $\phi=1.25$. Above this value, no further increase is observed, which is likely a self-absorption effect. Nevertheless, since both setups display the same behavior, this effect was neglected when comparing the trend of the atomic peaks ratios in the two acquisition setups. 


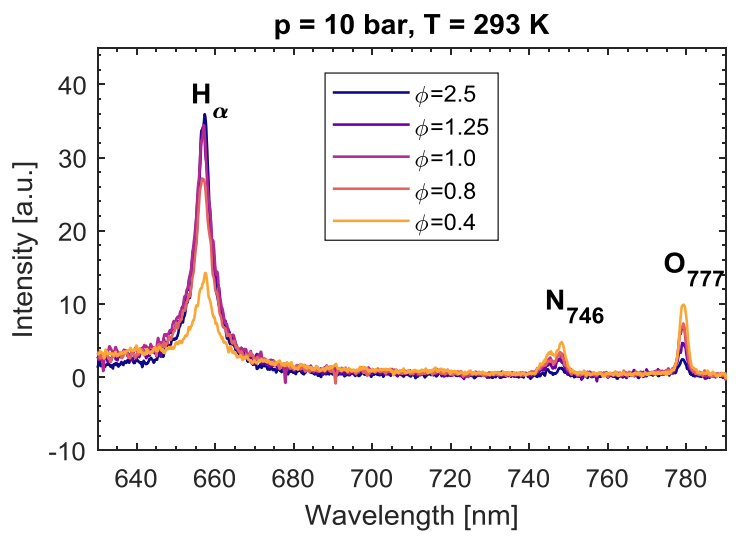

Figure 16: Spectra for different fuel-air equivalence ratios, fiber optic spark plug setup.

The effect of pressure variation of spectra acquired via fiber can be seen examining Figure 17, in which spectra acquired at stoichiometric mixture conditions for pressure ranging from 10 to 20 bar are shown.

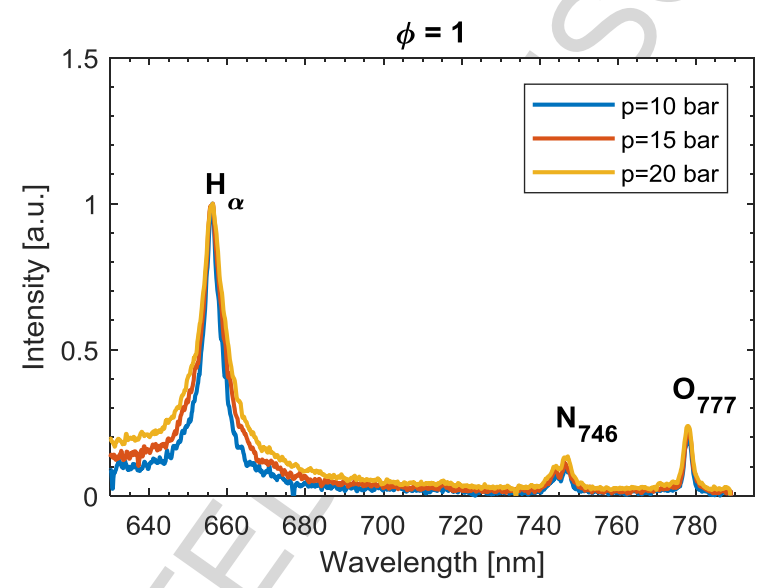

Figure 17: Spectra for different pressure values, fiber setup, normalized to $H_{\alpha}$ peak value.

Comparing Figure 16 with the corresponding spectra from the lens setup (Figure 6) it is clear that the signal to noise ratio is considerably lower for this setup, especially for the lowest pressure condition. Nevertheless, if the peak intensity ratios vs. fuel-air equivalence ratio obtained with fiber setup (

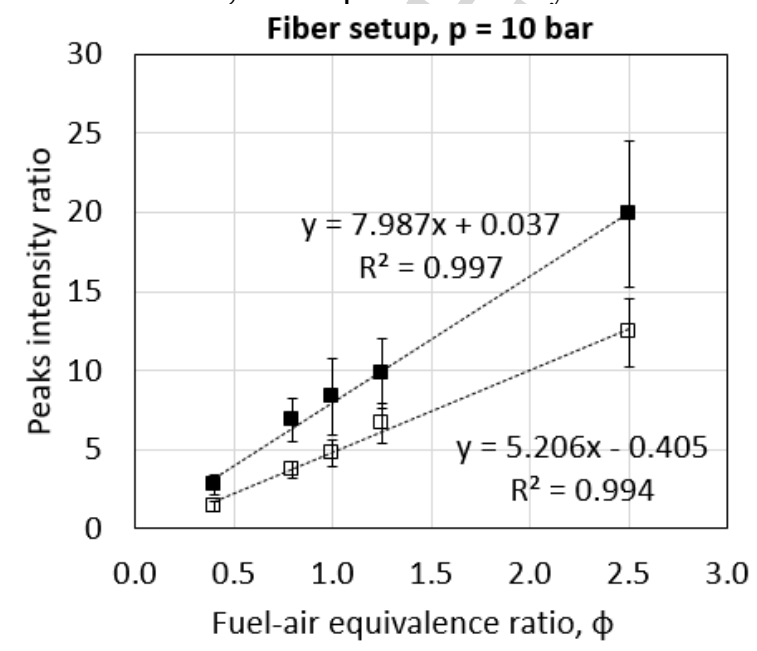

$\square \mathrm{H} / \mathrm{O} \cdot \mathrm{H} / \mathrm{N}$

Figure 18) at $\mathrm{p}=10$ bar are compared to the corresponding results obtained with lens setup (Figure 10), a similar linear trend can be derived. 


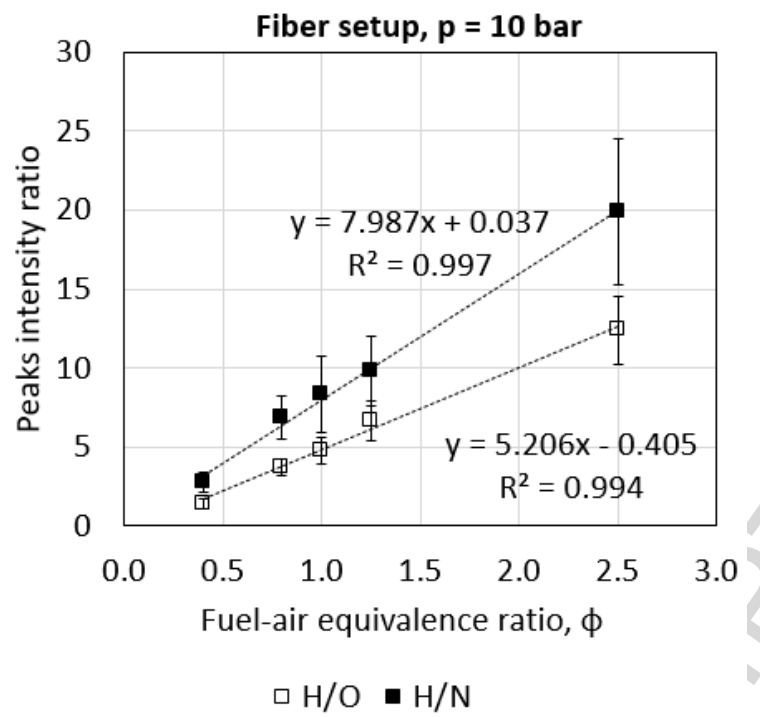

Figure 18: Peaks intensity ratios vs. $\phi$ at $\mathrm{p}=10 \mathrm{bar}$. Results obtained with the fiber optic spark plug setup.

Also when considering the pressure variation, the two different setups allow obtaining similar trends, as shown in Figure 19 and in Figure 20 for the $\mathrm{H} / \mathrm{O}$ and the $\mathrm{H} / \mathrm{N}$ intensity ratios v. pressure, respectively.

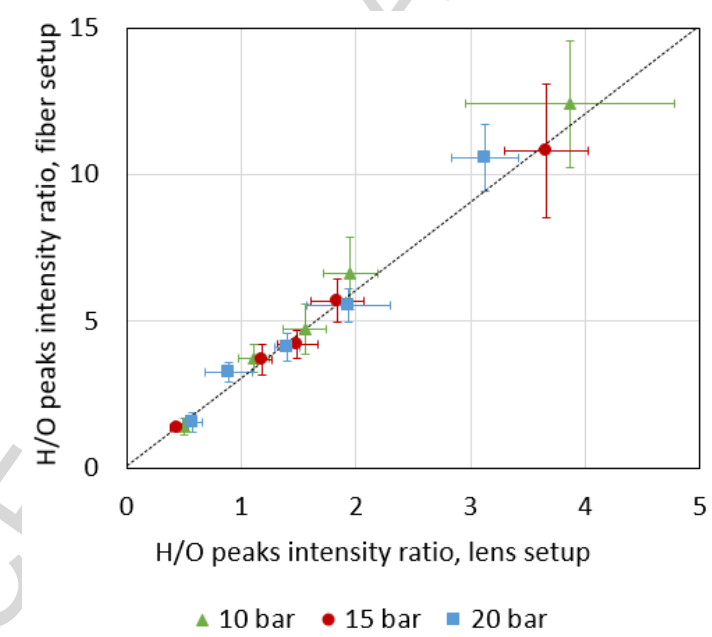

Figure 19: Comparison between H/O intensity ratios obtained with lens setup and fiber setup, at different pressure values.

The Figures depict the measured peaks intensity ratios for the same tests, acquired with the two different setups. The tests were performed at fuel-air equivalence ratios ranging from 0.4 to 2.5 , the higher intensity values corresponding to lower fuel-air equivalence ratios. Examining the figures, it can be seen that both $\mathrm{H} / \mathrm{O}$ and $\mathrm{H} / \mathrm{N}$ ratios tend to remain constant, within the experimental uncertainty, with increasing pressure. For both lens and fiber setup, standard deviation is higher for $\mathrm{H} / \mathrm{N}$ ratios and for higher fuel to air values, as discussed in the previous sections. If the percentage deviations with respect to mean values are considered, the fiber setup giv es similar results when compared to the lens setup. Namely, the percentage error for lens setup is $8.2 \%$ in the best case $(\mathrm{H} / \mathrm{N}$ at $2 \mathrm{O}$ bar) and $33 \%$ in the worst case (H/O at 15 bar). For the fiber setup, the percentage error ranges from $10.3 \%$ in the best 
case $(\mathrm{H} / \mathrm{N}$ at $20 \mathrm{bar})$ to $25 \%$ in the worst case $(\mathrm{H} / \mathrm{N}$ at $15 \mathrm{bar})$.

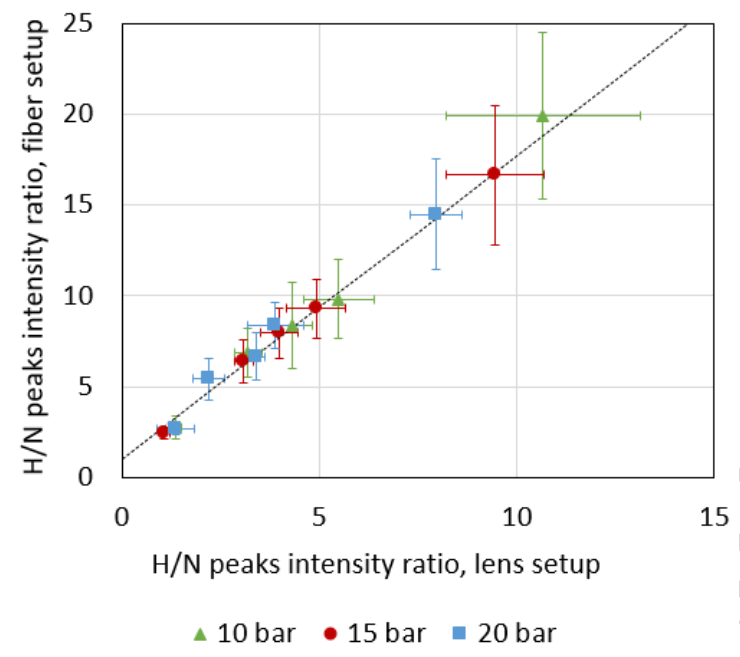

Figure 20: Comparison between H/N intensity ratios obtained with lens setup and fiber setup, at different pressure values.

The peak width in terms of FWHM measured for the same tests with the two different setups are compared in Figure 21. The experimental conditions are $\mathrm{p}=10,15$ and 20 bar and $\phi=0.4$. Also using the fiber setup, a linear trend is obtained for all the emission lines investigated, as was shown when reporting the lens setup case (Figure 15). Similar results were obtained for the other fuel-air equivalence ratio values tested, and are not reported here. The percentage error for the fiber setup ranges from $9.5 \%$ in the best case to $34.3 \%$ in the worst case. For the lens setup, the error ranges from $3.6 \%$ in the best case to $33.5 \%$ in the worst case. Interestingly, for both setups the best case corresponds to the oxygen peak at 20 bar, and the worst case to the nitrogen peak at 15 bar, thus confirming that the same effects are captured using the fiber setup or the lens setup.

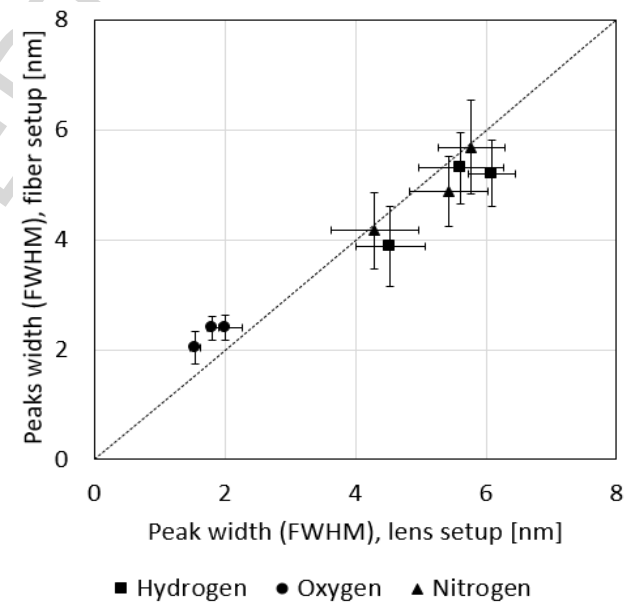

Figure 21: Comparison between the measured peaks' FWHM values for the lens setup and the fiber optic spark plug setup. Pressure $p=10-20$ bar, $\phi=0.4$

It can be therefore concluded that, despite the lower signal to noise ratio obtained with fiber optic spark plug when compared to the lens setup, the same trends are found when using lens setup or fiber setup. Namely, fuel-air equivalence ratio variation affects mainly the peaks intensity ratio, while negligible variations are observed in terms of peaks width; on the other hand, pressure increase 
determine a linear broadening of the peaks, while has no or little effect on peaks intensity ratios. Although the same overall phenomena are captured by different setups, a calibration specific for each setup is needed in order to obtain the correct estimation of the inv estigated parameters. Therefore, the proposed setup with the optical spark plug is a promising tool for local fuel-air equivalence ratio evaluation in gas mixtures at conditions relevant for engine applications.

Further investigation is ongoing with the aim to improve the signal to noise ratio for the fiber optic spark plug setup. Moreover, cross-sensitivities from other species such as $\mathrm{CO}, \mathrm{CO}_{2}, \mathrm{H}_{2} \mathrm{O}, \mathrm{NO}, \mathrm{NO}_{2}$ and $\mathrm{H}_{2}$ are being investigated. Such species are of interest when dealing with internal and ex ternal exhaust gas recirculation or hydrogen-enriched methane as a fuel for gas engines.

\section{Conclusions}

Spark-induced breakdown spectroscopy (SIBS) was used for the elemental characterization of premix ed methane/air mix tures, at different fuel-air equivalence ratios as well as operating conditions relevant to spark ignition engines. Focus was put on the spectral region from 630 to $790 \mathrm{~nm}$ with atomic emission lines of hy drogen $\left(\mathrm{H}_{\alpha}\right)$ at $656 \mathrm{~nm}$, nitrogen at $746 \mathrm{~nm}\left(\mathrm{~N}_{746}\right)$ and oxygen at $777 \mathrm{~nm}$ $\left(\mathrm{O}_{777}\right)$ because these three species are unique indicators of hydrocarbons and air. SIBS focusing on molecular species were reported earlier [36].

The discharge characteristics of the inductive ignition system were analyzed in order to gather information on the relationship between the spectral response and the electrical signals. In particular, it was shown that the presence of restrikes results in stronger continuum emissions, with the suggestion to limit the camera gating to $5 \mu$ s shortly after the initial breakdown.

The roles of pressure and temperature were discussed based on the results obtained testing spectral emissions from methane/air mixtures when pressure and temperature are changed in such a way that density is kept constant. Results confirm that spectral characteristics do not alter significantly for a given density.

Tests were therefore carried out to inv estigate the relationship between spectral emissions and fuel-air equivalence ratio, as well as pressure. Atomic emission lines of $\mathrm{H}, \mathrm{N}$ and $\mathrm{O}$ were used and the corresponding peak intensity ratios and peak widths (FWHM) were considered. It is shown that peak intensity ratios for $\mathrm{H} / \mathrm{O}$ and $\mathrm{H} / \mathrm{N}$ linearly increase for increasing fuel-air equivalence ratio, while the FWHM is constant for $\mathrm{N}$ and $\mathrm{O}$ emission lines, and only a slight variation was measured for $\mathrm{H}$. Pressure increase, on the other hand, results in linear peak broadening, while the peak intensity is only slightly affected, more prominently at fuel-rich conditions, where a decrease in peaks intensities is observed with increasing pressure. The results prove that the proposed diagnostic technique is feasible for fuel concentration measurements in the vicinity of the electrode gap during the discharge.

Finally, measurements acquired with the lens coupled spectrometer were compared to a fiber coupled setup with fibers embedded with a spark plug. Good agreement was obtained, even though for the fiber setup the signal to noise ratio is notably lower and the spatial resolution along the electrodegap is lost. The fiber coupled SIBS-based diagnostic technique is therefore a promising tool which can be transferred to running engine applications. 
Further investigation will be performed optimizing the signal to noise ratio for the fiber-coupled setup and to check for cross-sensitivities with other species present in engine environments. Additionally, work is ongoing in order to further characterize the plasma. Finally, engine test are planned in order to assess the reliability of the technique for fuel-air equivalence ratio measurements in real applications.

\section{Acknowledgements}

This study was conducted within the RENERG2-project of the Swiss Competence Center of Energy and Mobility as well as the GasOn project (European Union's Horizon 2020 research and innovation programme grant agreement No 652816) and financially supported by the Swiss Federal Office of Energy (SFOE, grant no. SI/500910-01), by the Swiss State Secretariat for Education, Research and Innovation contract number 15.0145-1, by Volkswagen Corporate Research and by the Research, Development and Promotion Foundation of the Swiss Gas Industry. Particular thanks go to C. Bach, W. Kreutner and K. Boulouchos for their discussions, support, advice and encou ragement, and to J. Rojewski for his contribution to 3 D rendering of the experimental setup.

\section{References}

[1] Benson, R.S., Whitehouse, N.D., Internal Combustion Engines, Pergamon press, 1979.

[2] Hey wood, J.B., Combustion and its modeling in Spark-Ignition Engines, in: International Sy mposium Comodia 94, 1994.

[3] Heywood, J.B., Internal Combustion Engine Fundamentals, McGraw-Hill, 1988.

[4] L. Cornolti, T. Lucchini, G. Montenegro, G. D’Errico, A comprehensive Lagrangian flame-kernel model to predict ignition in SI engines, Int. J. Comput. Math. 91 (2014) 157-174. doi:10.1080/00207160.2013.829213.

[5] U. Spicher, T. Heidenreich, Stratified-charge combustion in direct injection gasoline engines, in: Adv. Direct Inject. Combust. Engine Technol. Dev., Elsevier, 2010: pp. 20 -44. doi:10.1533/9781845697327.20.

[6] Aleiferis PG, Taylor AMKP, Ishii K, Urata Y, The nature of early flame development in a lean -burn stratified-charge spark-ignition engine, Combust. Flame.136(2004) 283-302. doi:10.1016/j.combustflame.2003.08.011.

[7] Y. Takagi, A new era in spark-ignition engines featuring high-pressure direct injection, Sy mp. Int. Combust. 27 (1998) 2055-2068. doi:10.1016/So o82-0784(98)80052-0.

[8] P. Danaiah, R. Kumar P, V. Kumar D., Lean Combustion Technology for Internal Combustion Engines: a Review, Sci. Technol. 2 (2012) 47-50. doi:10.5923/j.scit.20120201.09.

[9] J.H. Weaving, Stratified Charge Engines, in: J.H. Weaving (Ed.), Intern. Combust. Eng. Sci. Technol., Springer Netherlands, Dordrecht, 1990: pp. 137-171. doi:10.1007/978-94-009-07492 . 5 .

[10]T.D. Fansler, D.L. Reuss, V. Sick, R.N. Dahms, Invited Review: Combustion instability in spray guided stratified-charge engines: A review, Int. J. Engine Res. 16 (2015) 260-305. doi:10.1177/1468087414565675.

[11] R.M. Merer, J.S. Wallace, Spark spectroscopy for spark ignition engine diagnostics, SAETech. Pap. (1995). doi:10.4271/950164.

[12]J.C. Hilliard, G.S. Springer, Fuel Economy: in Road Vehicles Powered by Spark Ignition Engines, 1984.

[13]D.R. Ballal, A.H. Lefebvre, The influence of flow parameters on minimum ignition energy and quenching distance, Sy mp. Int. Combust. 15 (1975) 1473-1481.doi:10.1016/So o82$0784(75) 80405-X$.

[14]J. Koch, M. Schmitt, Y.M. Wright, K. Steurs, and K. Boulouchos, LES Multi-Cycle Analysis of the 
Combustion Process in a Small SI Engine, SAE Int. J. Engines 7.1 (2014) 269-285.

[15]A. Jamrozik, Lean combustion by a pre-chamber charge stratification in a stationary spark ignited engine, J. Mech. Sci. Technol. 29 (2015) 2269-2278. doi:10.1007/s12206-015-0145-7.

[16] G. Lucas, G. Tallu, M. Weißner, CFD-based Development of an Ignition Chamber for a lean and high efficient CNG Combustion, in: THIESEL 2018 Conf. Thermo- Fluid Dyn. Process. Direct Inject. Engines, 2018.

[17]E. Shapiro, I. Ahmed, N. Tiney, Advanced Ignition Modelling for Pre-chamber Combustion in Lean Burn Gas Engines, in: International Conference on Ignition Sy stems for Gasoline Engines, Berlin, 6-7 Dec. 2018, 2018.

[18]E. Shapiro, N. Tiney, P. Kyrtatos, M. Kotzagianni, M. Bolla, K. Boulouchos, G. Lucas, M. Weissner, Experimental and numerical analysis of pre-chamber combustion systems for lean burn gas engines, SAEInt. J. Engines 2019. (n.d.).

[19]N. Tiney, I. Hernández, M. Kotzagianni, P. Kyrtatos, K. Boulouchos, Flame-wall interaction modelling for pre-chamber combustion in lean burn gas engines, in: International CAE Conference and Exhibition, Vicenza, Italy, 8-9th Oct. 2018, 2018:p.8.

[20] C.C.O.B. Reynolds, R.L. Evans, Improving emissions and performance characteristics oflean burn natural gas engines through partial stratification, Int. J. Engine Res. 5 (2004) 105-114. doi:10.1243/146808704772914282.

[21]H. Biffiger, P. Soltic, Effects of split port/direct injection of methane and hydrogen in a spark ignition engine, Int. J. Hy drog. Energy. 40 (2015) 1994-2003. doi:10.1016/j.ijhydene.2014.11.122.

[22]W. Lee, J. Wu, Y. Lee, J. Sneddon, Recent Applications of Laser - Induced Breakdown Spectrometry: A Review of Material Approaches, Appl.Spectrosc. Rev. 39 (2004) 27 -97. doi:10.1081/ASR-120028868.

[23]L. Merotto, M. Sirignano, M. Commodo, A. D’Anna, R. Dondè, S. De Iuliis, Experimental Characterization and Modeling for Equivalence Ratio Sensing in Non-premixed Flames Using Chemiluminescence and Laser-Induced Breakdown Spectroscopy Techniques, Energy Fuels. 31 (2017) 3227-3233. doi:10.1021/acs.energyfuels.6bo3094.

[24]F. Ferioli, S.G. Buckley, Measurements of hy drocarbons using laser-induced breakdown spectroscopy, Combust. Flame. 144 (2006) 435-447. doi:10.1016/j.combustflame.2005.08.005.

[25]S. Joshi, D.B. Olsen, C. Dumitrescu, P.V.Puzinauskas, A.P. Yalin, Laser-induced breakdown spectroscopy for in-cylinder equivalence ratio measurements in laser-ignited natural gas engines, Appl. Spectrosc. 63 (2009) 549-554.

[26]M. Buschbeck, F. Büchler, T. Halfmann, S. Arndt, Laser-induced breakdown spectroscopy for lambda quantification in a direct-injection engine, Spectrochim. Acta Part B At. Spectrosc. 74-75 (2012) 103-108. doi:10.1016/j.sab.2012.06.051.

[27]T.X. Phuoc, F.P. White, Laser-induced spark for measurements of the fuel-to-air ratio of a combustible mixture, Fuel. 81(2002) 1761-1765. doi:10.1016/So 016-2361(02)00105-9.

[28]M.H. Morsy, Review and recent developments of laser ignition for internal co mbustion engines applications, Renew. Sustain. Energy Rev. 16 (2012) 4849-4875.doi:10.1016/j.rser.2012.04.038.

[29]R. Maly, Spark Ignition: Its Phy sics and Effect on the Internal Combustion Engine, in: J.C. Hilliard, G.S. Springer (Eds.), Fuel Econ., Springer US, Boston, MA, 1984:pp. 91-148. doi:10.1007/978-1-4899-2277-9_3.

[30]Griem, H.R., Spectral Line Broadening by Plasmas, Acad. Press, New Y ork, 1974.

[31] K.M. Abdul Rahman, N. Kawahara, D. Matsunaga, E. Tomita, Y. Takagi, Y. Mihara, Local fuel concentration measurement through spark-induced breakdown spectroscopy in a direct-injection hy drogen spark-ignition engine, Int. J. Hy drog. Energy. 41 (2016) 14283-14292. doi:10.1016/j.ijhydene.2016.05.280.

[32]N. Kawahara, E. Tomita, S. Takemoto, Y. Ikeda, Fuel concentration measurement of premixed mixture using spark-induced breakdown spectroscopy, Spectrochim. Acta Part BAt. Spectrosc. 64 (2009) 1085-1092. doi:10.1016/j.sab.2009.07.016.

[33]T.D. Fansler, B. Stojkovic, M.C. Drake, M.E. Rosalik, Local fuel concentration measurements in internal combustion engines using spark-emission spectroscopy, Appl. Phys. B Lasers Opt. 75 (2002) 577-590. doi:10.1007/s0 0340-002-0954-0.

[34]N. Kawahara, S. Hashimoto, E. Tomita, Spark discharge ignition process in a spark-ignition engine using a time series of spectra measurements, Proc. Combust. Inst. 36 (2017) 3451-3458. doi:10.1016/j.proci.2016.08.029.

[35]K. Kuwahara, H. Ando, Diagnostics of in-cylinder flow, mixing and combustion in gasoline engines, Meas. Sci. Technol. 11 (2000) R95-R111. doi:10.1088/0957-0233/11/6/202.

[36]T. Kammermann, W. Kreutner, M. Trottmann, L. Merotto, P. Soltic, D. Bleiner, Spark-induced breakdown spectroscopy of methane/air and hydrogen-enriched methane/air mixtures at engine relevant conditions, Spectrochim. Acta Part BAt. Spectrosc. 148 (2018) 152-164.

doi:10.1016/j.sab.2018.06.013. 
[37]D.A. Cremers, Handbook oflaser-induced breakdown spectroscopy, Second edition, Wiley, Hoboken, 2013.

[38]C. Parigger, D.H. Plemmons, J.O. Hornkohl, J.W.L. Lewis, Spectroscopic temperature measurements in a decaying laser-induced plasma using the C2 Swan sy stem, J. Quant. Spectrosc. Radiat. Transf. 52 (1994) 707-711.doi:10.1016/0022-4073(94)90036-1.

[39]C. Parigger, J.W.L. Lewis, D. Plemmons, Electron number density and temperature measurement in a laser-induced hydrogen plasma, J. Quant. Spectrosc. Radiat. Transf. 53 (1995) 249-255. doi:10.1016/0022-4073(95)90057-8.

[40] M. Sabsabi, P. Cielo, Quantitative Analysis of Aluminum Alloys by Laser-Induced Breakdown Spectroscopy and Plasma Characterization, Appl. Spectrosc. 49 (1995) 499-507. doi:10.1366/0003702953964408.

[41]M.A. Gigosos, V. Cardeñoso, New plasma diagnosis tables of hy drogen Stark broadening including ion dy namics, J. Phys. B At. Mol. Opt. Phys. 29 (1996) 4795-4838.doi:10.1088/o953$4075 / 29 / 20 / 029$.

[42]NIST, Atomic Spectra database, http://physics.nist.gov., (2019).

[43]N. Konjević, M. Ivković, N. Sakan, Hy drogen Balmer lines for low electron number density plasma diagnostics, Spectrochim. Acta Part BAt. Spectrosc. 76 (2012) 16-26. doi:10.1016/j.sab.2012.06.026.

[44]Soltic, P., Hilfiker, T., Hutter, R., and Hänggi, S., Experimental comparison of efficie ncy and emission levels of four-cylinder lean-burn passenger car-sized CNG engines with different ignition concepts, Accept. Publ. Combust. Engines. (2019). 
Highlights

- Optimized gating strategy found for atomic spectral emissions acquisition

- Pressure and temperature change at constant density do not alter spectral emissions;

- Spectral features correlate with fuel-air equivalence ratio and pressure

- Possibility for running engine application of the SIBS technique is envisaged 